\title{
Basal Root Rot, a new Disease of Teak (Tectona grandis) in Malaysia caused by Phellinus noxius
}

\author{
Mohd Farid A. ${ }^{2}$, Lee S. S. ${ }^{2}$, Maziah, Z. $^{1^{\star}}$, Rosli, H. $^{2}$ and Norwati, M. ${ }^{2}$ \\ ${ }^{1}$ School of Biological Sciences, Universiti Sains Malaysia, 11800 Minden, Penang, Malaysia. \\ ${ }^{2}$ Forest Research Institute Malaysia (FRIM), Kepong Kuala Lumpur. \\ Email: ried@frim.gov.my
}

\begin{abstract}
Basal root rot of teak was first reported from Sabak Bernam, Selangor making this the first report of the disease on teak in Peninsular Malaysia. The fungus found associated with the disease was Phellinus noxious. The disease aggressively killed its host irrespective of the host health status. Bark depression at the root collar which was visible from a distance was the characteristic symptom and the main indicator in identifying the disease in the plantation since above ground symptoms of the canopy could not be differentiated from crowns of healthy trees. However, although above ground symptoms were not easily discernible, the disease was already advanced and the trees mostly beyond treatment; $3.4 \%$ of the trees in the plantation were affected and the disease occurred both on solitary trees and in patches. Below ground, infected trees had rotted root systems, mainly below and around the collar region with brown discolored wood and irregular golden-brown honeycomb-like pockets of fungal hyphae in the wood. Pathogenicity tests showed that the fungus produced symptoms similar to those observed in the plantation and killed two year-old teak plants. The disease killed all the inoculated hosts within three months, irrespective of wounded or unwounded treatments.
\end{abstract}

Keywords: forest plantation, Phellinus noxius, root disease, Tectona grandis

\section{INTRODUCTION}

Teak (Tectona grandis) is one of the most valuable timber trees in Southeast Asia due to its excellent wood properties. The wood is durable, has sound dimensional stability, an attractive natural colour and is valuable for high quality furniture and interior finishing. This relatively fast growing species of the family Verbenaceae, can achieve a maximum height of approximately $85 \mathrm{~m}$ (Hashim and Mohd Noor, 2002). Teak trees in India and Myanmar are known to be able to achieve diameters of between $91 \mathrm{~cm}$ to $213 \mathrm{~cm}$ (Kadambi, 1972). In Peninsular Malaysia, the species can grow up to $45 \mathrm{~m}$ in height and $100 \mathrm{~cm}$ diameter in 40 years (Ahmad Zuhaidi et al., 2002). Such promising characteristics have encouraged many Malaysian farmers to invest in planting teak either on a small or large scale. So far, approximately 18,000 ha of land have been converted to teak plantations throughout Peninsular Malaysia (Krishnapillay and Ong, 2003). These plantations were established on various types of soil, in areas of differing previous landuse, using different techniques of land preparation, silviculture treatments and seed sources. Interest in teak plantation establishment boomed in the early 1990's, yet little is known about the impact of the most damaging maladies, which are mainly root diseases.

From preliminary surveys conducted throughout Peninsular Malaysia, incidence of root disease on teak was found to be low. However, other diseases such as stem canker and foliage diseases, mainly leaf rust and yellowing, were common. Observations by Maziah and

*Corresponding author
Lee (1999) revealed that trees above two years old were more susceptible to white root disease, probably due to the presence of a well-developed root system. The disease was reported to occur in newly established plantations, with above ground symptoms such as gradual wilting of leaves and shriveling of the whole plant (Maziah and Lee, 1999). Below ground, white rhizormorphs covered the root surface of rotting root systems. This was followed by death of the trees.

In Malaysia, Basal Root Rot (BRR) disease was found in teak plantations at Sabak Bernam, Selangor (Mohd Farid et al. 2005). The severity of the disease is still low but it has the potential to destroy the plantations if no measures are taken to control or manage it. The disease was observed to aggressively kill trees, irrespective of health status. Usually, when above ground symptoms appear, it is too late for treatment. Prevention approaches during land preparation are the most preferred techniques in avoiding the disease in future. In Papua New Guinea (Shaw 1984; Arentz, 1990), Java and Tanganyika (Bakshi, 1964), Phellinus noxius Corner has been reported to be the causal agent of basal root rot in teak plantations. However, little is known about the severity of the disease in these countries.

Therefore, this study was undertaken to identify the pathogen-causing BRR as well as to make early diagnosis of the disease in the field. This information would enhance our capability in identifying the disease and thus assist us in determining the most effective control measures. 


\section{MATERIALS AND METHODS}

\section{Disease survey and plot establishment}

General surveys for root disease in plantation-grown teak were conducted in Peninsular Malaysia beginning in 1997. Disease incidence was documented and information on the prior landuse of the area, land preparation techniques and silviculture treatments applied was collected. In July 1999, two teak plantations at Sabak Bernam, Selangor, Malaysia were identified as having been moderately affected by root disease. These plantations were designated as plantation $A$ and plantation $B$. Numbers of standing trees and trees with disease symptoms in both the plantations were recorded. Two study plots were established, namely plot 1 (1166 trees) in plantation A and plot 2 (900 trees) in plantation B to study the severity of the incidence and spread of the disease in both the plantations.

\section{Background of the plantations}

The two plantations were formerly coconut (Cocos nucifera) plantations integrated with cocoa (Theobroma cacao). The areas were converted to teak plantations in April 1994 and agroforestry concepts were implemented to fully utilize the areas. During land preparation, most of the old coconut and cocoa stumps were completely removed and the remaining debris buried in the soil. Most of the coconut stems were placed in rows and burned while quality stems were extracted for public utility. Both the areas are low-lying and the soil locally known as Bernam series (Eutric Gleysols) consists of a cambic horizon and an aquic moisture regime (FAO/UNESCO, 1974). This soil was developed from marine clay by drainage. One-year-old teak seedlings were obtained from the Forest Research Institute Malaysia (FRIM) and planted at $2.5 \mathrm{~m} \times 2.5 \mathrm{~m}$ spacing in both plantations. Drainage ditches were made using an excavator by digging a row for water outlet per two planting lines in plantation $A$ and a row for water outlet per three planting lines in plantation $B$.

\section{Root disease inspection}

Monitoring of root disease in both plots was conducted at 4-monthly intervals. A complete assessment was used to determine the severity of the infection and disease symptoms such as presence of fruiting bodies, rotting of root collar, yellowing of leaves, defoliation, reduction in canopy size and others were documented. Roots of diseased trees were sampled and the samples transported back to the Pathology Laboratory at FRIM for isolation of the suspected causal organism(s). Tissues bearing disease symptoms were cut into several pieces of approximately $3 \mathrm{~mm} \times 3 \mathrm{~mm}$ size, plated onto Potato Dextrose Agar (PDA) and incubated at room temperature $\left(28^{\circ} \mathrm{C} \pm 2^{\circ} \mathrm{C}\right)$ for the fungus to grow. The cultures were then transferred onto Malt Extract Agar (MEA) for morphological studies. Both macroscopic and microscopic features of the fungal cultures and basidiocarp were described according to Stalpers (1978) and Nunez and Ryvarden (2000).

\section{Pathogenicity tests}

A pathogenicity test was conducted to determine the causal organism of BRR in teak by infecting 20 healthy, potted 2 year-old teak saplings with 1 month-old inoculum blocks (Lee and Noraini Sikin, 1999) at the root collar. Inoculum consisted of pieces of rubberwood branches measuring about $2 \times 10 \mathrm{~cm}$ which had been inoculated with $P$. noxius (isolate FRIM 618). Isolate FRIM 618 was obtained from a diseased teak root collected from Sabak Bernam, Selangor and had been identified as $P$. noxius based on the fruiting bodies produced using the methods described by Lee and Noraini Sikin (1999). The test was conducted twice using different soil compositions since the first test with a 3:2 ratio of soil to sand failed. The test was repeated using a growth substrate of soil, sand and peat at a ratio of 3:2:1. Aggressiveness of the pathogen was studied by equally dividing the planting materials into two treatments namely wounded and unwounded. In the wounded treatment, saplings were injured with a knife by making a shallow $1-2 \mathrm{~cm}$ wide wound on the taproot, approximately $2 \mathrm{~cm}$ below ground surface (Mohd Farid et al., 2001). Two pieces of the well colonized, one-month old $P$. noxius blocks were buried at a depth of about $5 \mathrm{~cm}$ in contact with the tap root of six saplings from each treatment. The remaining saplings in each treatment were not inoculated and kept as controls. Pathogenicity development was observed and recorded at weekly intervals over a 6-month period.

\section{RESULTS AND DISCUSSION}

\section{Disease survey and above ground symptoms}

Disease surveys conducted since 1997 found that most teak plantations in Peninsular Malaysia were free from root diseases. However, poor growth performance, foliage diseases and pest problems were the most common tree health problems occurring in the plantations. These were the major problems faced by the farmers mainly in the first phase of the plantation establishment. The majority of the problematic plantations were found to be generally linked to species-site intolerance, improper planting techniques and poor silviculture management. Those trees exhibiting poor growth were frequently observed to possess underdeveloped and coiling root systems in the planting hole.

Apart from that, leaf rust caused by Olivea tectonae was the main leaf disease found in the plantations. This is an air-borne pathogen that is favoured by hot and dry weather (Gibson, 1975). Teak skeletonizer (Paliga damastesalis) and woodborer (Xyleutus ceramica) were the major pests found in most of the surveyed plantations. Severity of $P$. damastesalis infestation was low in the plantations, however, it can cause serious defoliation in young teak plantations (Intachat et al. 1999). X. ceramica 
is the most common wood borer found in Malaysia and infestation by this species has not caused mortality of the infested trees (Intachat, 2002).

Previous disease surveys in Sabak Bernam had found BRR to be the major destructive disease in both the 10 year-old teak plantations. More recent surveys carried out in 2002 and 2003 revealed that the number of trees killed by BRR was gradually increasing over time in both the plantations especially in plot 1 . The percentage of dead trees in plot 1 and plot 2 during the last survey in 2003 were $4.37 \%$ of 1166 trees and $2.11 \%$ of 900 trees respectively. The dead trees occurred in isolation and in groups, indicating that inoculum sources were randomly distributed in the soil. Further examination of the root systems revealed the spread of the disease to adjacent trees through root contact, mainly within planting rows. This phenomenon was clearly observed as patches of symptomatic or dead trees and wider canopy openings (Figure 1). However, spread of the disease to adjacent trees that were separated by drainage trenches was much less. This suggests that the trenches are a sound cultural strategy in minimizing spread of the disease to other planting rows. Construction of isolation trenches is the most common and popular method of root disease control in plantations to prevent disease spread (Maziah and Lee, 1999).

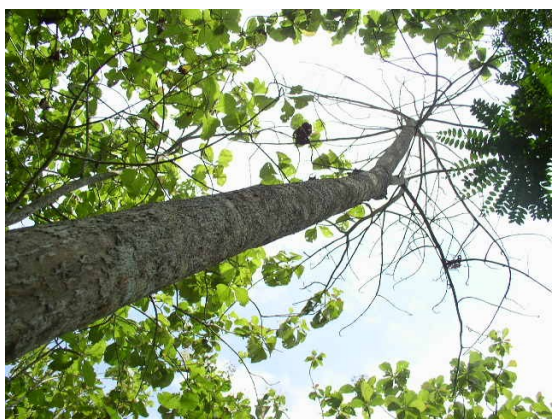

Figure 1: Defoliation and open gaps are the most advanced symptoms of the disease.

On diseased trees, the above ground symptoms were almost similar to those of other root diseases. Externally, advanced stages of the infection were obviously detectable, as indicated by bark depression, rotting at the root collar and signs of the presence of woodborers on the rotted portions, such as insect frass, bore holes and larvae on the affected trees (Figure 2 and 3). These symptoms and signs could be found on the tree stem up to $40 \mathrm{~cm}$ from ground level. However, in the absence of such symptoms and signs, early stages of infection were difficult to diagnose in the plantations. In addition, most of the trees had uniform canopy size and were of comparable health status due to the close planting distance and lack of thinning. Several affected trees were wind thrown, as the anchoring root system had been severely decayed.

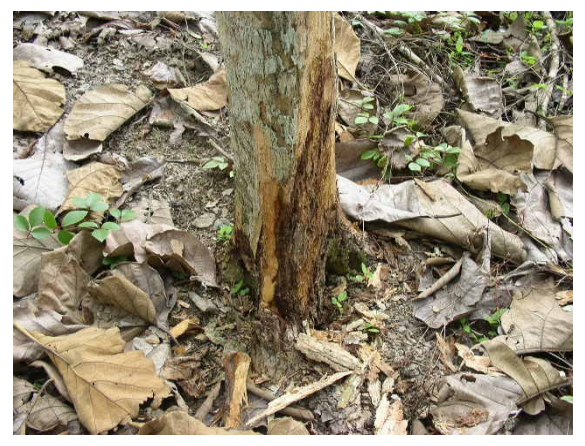

Figure 2: Rotting of root collar region advancing up the tree stem as indicated by the arrow.

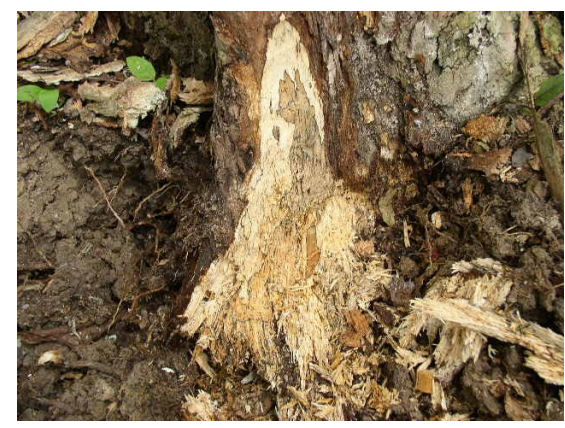

Figure 3: Rotting and fibrous root system indicating that the tree is in the advanced stage of the disease.

\section{Underground symptoms and fungal $\mathrm{pH}$ tolerance}

Below ground symptoms observed, include the presence of dark brown decayed zones and irregular golden-brown pockets of hyphae in the roots. In the bark, diseased zones were clearly distinguishable by the presence of dark brown discolored patches, which were soft and friable when crushed with fingers. In the wood, the diseased zones were indicated by pale brown discoloration but the wood structure remained tough even though it had been penetrated by the fungal hyphae. In the majority of the dead trees the fungus had penetrated the wood, rotting the root systems, and progressed upwards to girdle the root collar. In several of the severely affected trees, irregular pockets of golden-brown hyphae were common. This symptom was also observed in Acacia mangium root rot caused by $P$. noxius (Lee and Noraini Sikin, 1999). At this stage, the affected roots were soft, fibrous and totally rotted.

In some trees, brownish to dark brown resupinate basidiomata of $P$. noxius were found, forming a sock-like wrapping around the root systems. Usually, the fungus is localised in the lateral roots and in the taproot near the root collar (Nandris et al., 1987). This rhizomorph becomes encrusted with age, turning a dark brown colour with clay soil adhering to the root surface. This habit is 
almost similar to that of brown root disease caused by $P$. noxius on sentang (Azadirachta excelsa) (Mohd Farid et al., 2001). In sentang there was usually sand adhering to the rhizormoph but this was not found in teak BRR. This unique characteristic is among the main indicators used in diagnosis of brown root rot caused by $P$. noxius (Anon, 1974; Nandris et al., 1983; Nandris et al., 1987; Ann et al., 1999). This pathogen is a facultative parasite when susceptible hosts and disease conducive conditions are present but becomes saprophytic under adverse conditions or when an ample food base is absent (Browne, 1968).

In this study, both the plantations are located on marine clay soil areas that consisted mainly of high clay content with very fine sand. Therefore, coarse soil particles and sand were not present and did not adhere to the affected root surface. However, fine and dark organic particles were often found adhering to the diseased roots and this was probably due to the plantations being manually cleared followed by burning of the coconut tree residues. In addition, presence of the mixed acid Isohyperthemic Typic Tropaquepts soil of Bernam series that can produce acid sulfate during the dry season could also enhance the fungal aggressiveness in killing the trees. Ann et al. (1999) found that $P$. noxius preferred acidic conditions and did not grow at $\mathrm{pH}$ values higher than 7.5. They also consistently observed that all diseased soils infested with $P$. noxius had $\mathrm{pH}$ values equal to or lower than 5.0. In this case, soil pH values of plantations $A$ and $B$ were 4.4 and 4.6 , respectively. These values indicated that $P$. noxius obtained from both plantations could survive in more acidic soil conditions.

\section{Morphological characteristics of $P$. noxius}

The pathogen of BRR is a member of the basidiomycetes in the order Hymenochaetales. On MEA, the growth rate of $P$. noxius was $0.7 \mathrm{~cm} /$ day with the initially white surface of the culture gradually turning brown over time, especially near the inoculum source. The texture of the mycelial mat was crustose. The species is dimitic due to the presence of both generative hyphae and skeletal hyphae in the culture. The generative hyphae were brown, simple septate (3.2- $x \quad 8.8 \mu \mathrm{m}$ wide) and without clamp connections. Whereas, the skeletal hyphae were 3.2-4.2 $\mu \mathrm{m}$ wide, non-septate, brown in colour and thick walled. Brown dendritic hyphae were abundant in culture (Figure 4a.). A brown to dark brown, thin and encrusted cuticlelike layer is always formed on old cultures. However, setae were not produced although the cultures were placed under cyclic ultra violet (u.v) light and dark conditions at room temperature in efforts to induce setae formation.

The fruiting body of the fungus was resupinate, perennial, flat and broadly attached to the substrate with a woody, hard consistency (Figure 4b.). The pilear surface was finely velvety and pale ferruginous to umber in older regions or concentric zones, glabrous, dark brown to black, resinous, with a hard crust and thinner towards the margin. Pores were small and round, usually invisible to the naked eye. Inside the pores white mycelial strands oriented radially were observed. Both skeletal and generative hyphae were present in the basidiocarp. The generative hyphae were simple septate, thin-walled, pale yellowish and 2-4 $\mu \mathrm{m}$ wide. Skeletal hyphae were yellow to bay and 4-6 $\mu \mathrm{m}$ wide. Setal hyphae were abundant, thin-walled, dark brown to ferruginous, obtuse, $100 \times 7.5-$ $13 \mu \mathrm{m}$ (Figure 4c.). Basidiospores were subglobose, 2.87$4.98 \times 2.62-3.40 \mu \mathrm{m}$, hyaline and thin walled (Figure $4 \mathrm{~d}$.).

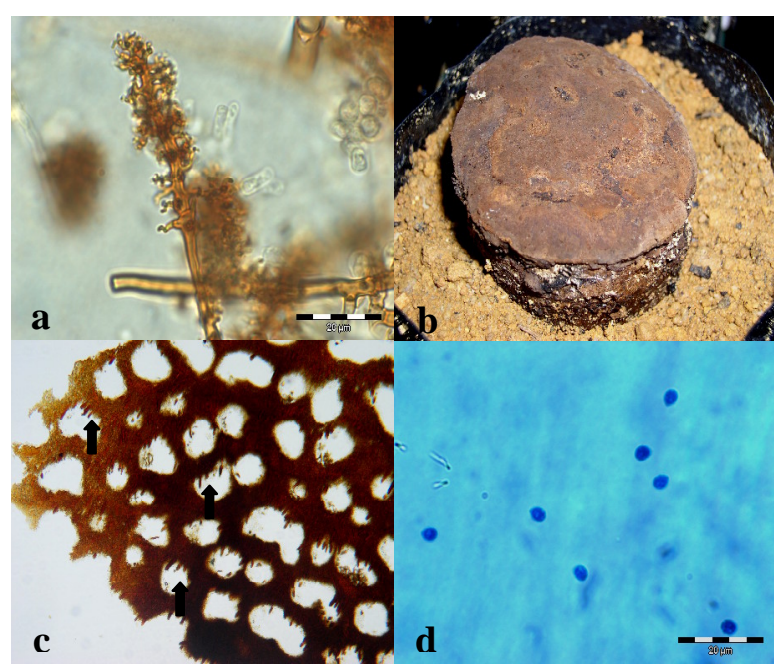

Figure 4: Among the major characteristics of $P$. noxius: (a) dendritic hypha, (b) resupinate fruiting body, (c) presence of setae inside the pores as shown in crosssection (arrows) and (d) subglobose shaped, hyaline and thin walled basidiospores (at 100x magnification and stained with lectophenol blue) .

\section{Pathogenicity tests}

The pathogenicity tests revealed that $P$. noxius killed all the saplings irrespective of the wounded or unwounded treatments. This fungal pathogen causes brown root rot of many woody species including important agricultural crops such as oil palm, cocoa, rubber, tea and fruit trees (Pegler, 1968; Wood and Lass, 1985; Nandris et al., 1987a; 1987b; Chang, 1995; Ann et al,. 2002). It could also be a major threat to forest plantations in the tropics.

The test showed that the above ground symptoms were almost similar to those observed on the affected trees in the plantations. Yellowing of leaves, wilting and defoliation were among the major symptoms. However, the early stages of infection could not be distinguished. This perhaps indicates why it was so difficult to diagnose early BRR infection of teak in the field. Above ground symptoms mostly appeared six weeks after inoculation as yellowing and poor leaf size development. At this stage, the inoculum blocks were found to be strongly bound to the roots indicating that the roots had been invaded by the fungal hyphae. 
The affected root surface turned dark brown and became rotten and this rot gradually progressed onto the taproot and other lateral roots. The host was only killed when rotting symptoms appeared around the root collar or when half of the root system of a particular plant was affected. These symptoms mostly appeared eight to eighteen weeks after inoculation, probably depending on the host resistance. Wilting, shrinking of the stem, coppicing and defoliation were the most common symptoms of advanced pathogenesis. At this stage, the below ground symptoms were very similar to those observed on diseased trees in the field. However, coppicing rarely occurred on teak in both the plantations. The points of attachment to the inoculum blocks were rotted and fibrous, while brownish to dark brown fungal hyphae covered the lateral roots. The rotted portion was observed to advance towards the root collar, finally forming a bark depression. Fine soil particles such as sand and decomposed organic materials were also found adhering to the hyphae. This indicates that different soil compositions gave rise to the slightly different below ground symptoms in the plantations and in the in-vitro experiment. The first pathogenicity test failed probably due to poor soil moisture retaining properties of the potting media. This unconducive environment probably retarded fungus development, thus preventing it from becoming pathogenic to the host.

\section{CONCLUSION}

At present, the disease is found only at Sabak Bernam, Selangor with $P$. noxius as the pathogen. BRR is a potentially important disease due to its ability to kill trees irrespective of the tree health status and size. Gradual appearance of above ground disease symptoms associated with advanced stages of the disease is a major constraining factor in early detection of the disease. Early stages of infection were mostly indistinguishable from healthy trees while advanced stages of the infection were obviously visible as indicated by bark depression, rotting at the root collar, wider canopy gap and frequent presence of woodborers at the rotted portions. Below ground symptoms while present even during early stages of the disease are, however, only detectable upon excavation which involves extensive labour. Pathogenicity tests revealed that the fungus did not require the presence of wounds to invade and subsequently kill the host plant. Further studies are required for early detection and diagnosis of the disease to prevent or reduce the spread of the disease.

\section{REFERENCES}

Ahmad Zuhaidi, Y. Zakaria, I and Rosdi, K. (2002). Species for Timber Plantations. A Manual For Forest Plantation Establishment in Malaysia. Malayan Forest Records. Forest Research Institute Malaysia, Kuala Lumpur. 45: 13- 32.

Ann, P.J., Lee, H.L. and Huang, T.C. (1999). Brown Root Rot of 10 Species of Fruit Trees Caused by Phellinus noxius in Taiwan. Plant Disease. 83(8): 746- 750.

Ann, P.J., Chang, T.T. and Ko, W.H. (2002). Phellinus noxius Brown Rot of Fruit and Ornamental Trees in Taiwan. Plant Disease. 86(8):820- 826.

Anon (1974). Root Diseases of Hevea. Planter's Bulletin of the Rubber Research Institute Malaysia. 133:109200.

Arentz, F. (1990). Proceedings of the $3^{\text {rd }}$ International Conference on Plant Protection in the Tropics Vol. IV. Genting Highlands. Malaysian Plant Protection Society. pp. 151- 155.

Bakshi, B.K. (1964). Diseases of Widely Planted Forest Trees. FAO/ IUFRO Symp. Inter. Dang. For. Disease and Insects, Oxford. pp. 234 - 237.

Browne, F.G. (1968). Pest and Disease of Forest Plantation Trees. An Annotated List of the Principle Species Occurring in the British Commonwealth. Clarendon Press, Oxford. pp. 1330.

Chang, T.T. (1995). A Selective Medium for Phellinus noxius. EuropeanJournal of Forest Pathology. 25: $185-190$

FAO/UNESCO (1974). FAO- Unesco Soil Map for the World.

Gibson, I.A.S. (1975). Diseases of Forest Trees Widely Planted as Exotic in the Tropics and Southern Hemisphere. In: Part 1. Important members of the Myrtaceae, Leguminoseceae, Verbenaceae and Meliaceae. Dept. of Forestry, Oxford Univ. and Com. Mycol. Inst. Kew. Surrey, England. pp. 37- 41.

Hashim, M.N. and Mohd Noor, M. (2002). Tectona grandis. A Manual for Forest Plantation Establishment in Malaysia. Malayan Forest Records. Forest Research Institute Malaysia, Kuala Lumpur. 45: 245- 258.

Intachat, J. Mastura, M. and Ng. L.T. (1999). The Teak Skeletoniser and Its Potential Control in Malaysia. Proceedings of the $5^{\text {th }}$ International Conference on Plant Protection in the Tropics, Kuala Lumpur, Malaysia. pp. 75- 78.

Intachat, J. (2002). Plantation Forest: Insect Pests. A Manual For Forest Plantation Establishment in Malaysia. Malayan Forest Records. Forest Research Institute Malaysia, Kuala Lumpur. pp. 115 - 124.

Kadambi, K. (1972). Silviculture and Management of Teak. Bulletin 24. School of Forestry Stephen F. Austin State University, Nacogdoches, Texas. pp 136.

Krishnapillay, B and Ong, T.H. (2003). Private Sector Forest Plantation Development in Peninsular Malaysia. Information and analysis for sustainable forest management: Linking national and international efforts in South and Southeast Asia. FAO, Bangkok, Thailand. pp 36

Lee, S.S. and Noraini Sikin, Y. (1999). Fungi Associated with Heart Rot of Acacia Mangium Trees in Peninsular Malaysia and East Kalimantan. Journal of Tropical Forest Science: 11(1): 240 -254.

Maziah, Z. and Lee, S.S. (1999). Diseases and Disorders of Teak (Tectona grandis) in Peninsular Malaysia. Proceedings of the $5^{\text {th }}$ International 
Conference on Plant Protection in the Tropics, 15 18 March 1999, Kuala Lumpur. pp. 158 - 163.

Mohd Farid, A., Maziah, Z., Ab. Rasip, A.G. and Noraini Sikin, Y. (2001). Preliminary Study on Pathogenicity of Three Root Disease Fungi on Azadirachta excelsa (sentang). Journal of Tropical Forest Science: 13 (3): 554- 558.

Mohd Farid, A., Lee, S.S., Mohd Rosli, H., Maziah, Z. and Norwati, M. (2005). Incidence of teak basal root rot caused by Phellinus noxius in Malaysia. Australasian Plant Pathology. 34: 1-2.

Nandris, D., Nicole, M., Geiger, J.P and Mallet, B. (1983). Root Rot Disease in the Forests and Plantations of the Ivory Caost. Proceedings of the Sixth International Conference on Root and Butt Rots of Forest Trees. Melbourne Victoria and Gympie, Queensland, Australia. August 25- 31, 1983. pp. 286 $-295$

Nandris, D., Nicole, M. and Geiger, J.P (1987a). Root Rot Disease of Rubber. Plant Disease. 71(4): 298306.
Nandris, D., Nicole, M. and Geiger, J.P (1987b) Variation in virulence among Rigidoporus lignosus and Phellinus noxius isolates from West Africa. European Journal of Forest Pathology .17: 271- 181.

Nunez, N. and Ryvarden, L. (2000). East of Asian Polypores. Volume 1: Ganodermataceae and Hymenochaetaceae. Fungiflora, Oslo, Norway. pp 168.

Pegler, D.N. and Waterston, J.M. (1968). Phellinus noxius. C.M.I. Descriptions of Pathogenic fungi and Bacteria. No. 195.

Shaw, D.E. (1984). Microorganisms in Papua New Guinea. Research Bulletin. No. 3, Department. of Primary Industry, Port Moresby. pp 344.

Stalpers, J.A. (1978). Identification of wood-inhibiting Aphyllophorales in pure culture. Studies in Mycology No. 16. Institute of Royal Netherlands Academy of Arts and Sciences. pp 248.

Wood, G. A. R. and Lass, R.A. (1985). Cacoa. Longman, New York. pp 556. 